\title{
Seen and heard: The youth as game-changing role- players in climate change and environmental consciousness - A South African perspective
}

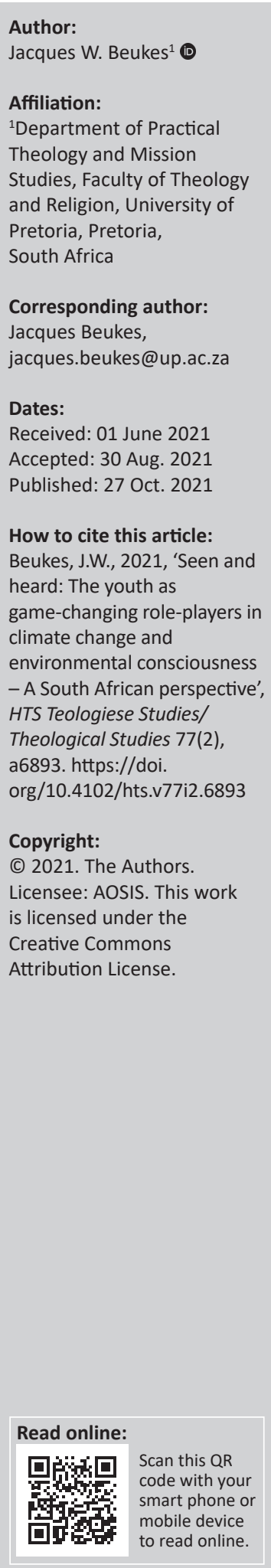

The environmental crisis, ecological injustice and climate change are some of the biggest challenges to humanity and sustainable development worldwide. The youth are at the centre of the ecological (in)justice, environmental consciousness and climate change discourse. For the youth to participate and influence development with regard to the climate crisis in a favourable way, they must understand their role and the issues and challenges that they face in this regard.

Contribution: The aim of this explorative article is twofold. It highlights the involvement of the South African youth in ecological matters. It also offers insights on why the youth can be regarded as game-changing role-players with regard to the climate crisis and being environmentally conscious.

Keywords: youth; climate change; environmental; sustainable development; sustainable development goals (SDGs).

\section{Introduction}

Environmental destruction and climate change are globally amongst the most threatening challenges to humanity and sustainable development. Similarly, in South Africa also, climate change threatens homes, health and the natural resources which many people depend on for survival. According to Awojobi and Tetteh (2017:39), it is predicted that Africa will be one of the areas that will be hit the hardest by climate change. This is because it is the most vulnerable continent in this regard (Awojobi \& Tetteh 2017:39). The population that will be affected the most is the children and the youth (Cattell 2021; Chersich et al. 2019; Han \& Ahn 2020; Nkrumah 2021).

According to 2019 mid-year population estimates, the South African population consists of 58.8 million people. Of which, 17 million are children between the ages of $0-14$ years and 20.6 million are youth between the ages of 15-34 years. This means that the majority (63.9\%) of the South African population is children and youth (Statistics South Africa 2019). ${ }^{1}$ In the traditional South African society, it was understood for many years that children should be seen but not be heard (Nel 2016:1). However, the young people of today find themselves right in the centre of debates about ecological (in)justice, environmental consciousness amongst the different generations and climate change discourses and practices. In the current scenario, where children and the youth are being affected the most by climate change, the traditional understanding of children be seen but not heard has been changed by the youth of today. This is because they are the one's who will inherit the problems and burdens of greenhouse gas emissions (GHGs), pollution and other environmental hazards (Chersich et al. 2019:615).

For the youth to participate and influence development with regard to the climate crisis in a favourable way, they must understand their role and challenges that they face in this context. Given this scenario, the youth need to actively address problems with regard to the climate crisis. Instead of being victims, they should be seen as solution providers. The youth can meaningfully contribute towards climate-resilient development, provided that an enabling environment is created.

Various youth movements across the globe, such as Fridays for Future, Sunrise and the Extinction Rebellion (to name just a few), have started to acknowledge this problem. They have also ensured 1.See http://www.statssa.gov.za/?p=12362.

Note: Special Collection: Youth, Faith, Climate Change and Environmental Consciousness: A Case for Sustainable Development, subedited by Jacques Beukes (University of Pretoria), Juliane Stork (Humboldt University, Berlin) and Ignatius Swart (University of the Western Cape) 
that this crucial challenge remains on the global agenda of various political leaders, countries, churches, and so on. Moreover, the youth themselves have started to become active game-changing role-players. This is because they acknowledge the need to actively address the climate crisis as solution providers and not as victims. In fact, I want to draw on the view of Han and Ahn (2020:2) that the youth can be regarded as the environmental stewards of the future.

The previously mentioned youth movements are all international movements. Therefore, this article differs from the previously mentioned literature as it specifically aims to explore how the South African youth are involved in environmental issues. Hence, I will briefly focus on climate change as a current phenomenon, followed by how this crucial topic is linked to the Sustainable Development Goals (SDGs). Subsequently, the youth's involvement and the effect thereof will be explored, and finally, I will focus on why the youth can be regarded as game-changing role-players.

\section{The climate change phenomenon and its impact on the youth in South Africa}

Climate change is not new. Since the Industrial Revolution in the 1700s, GHGs have risen. This has raised the average temperature on earth by more than $1{ }^{\circ} \mathrm{C}$ (Nkrumah 2021:2). Despite this, climate change has only received attention during the last 40 years, and it has become more prominent on a worldwide scale during the last decade. In the South African context, issues around climate change gained growing prominence only during the last few years (Conradie 2008:2). There are numerous scientific reports on the imminent impact of the climate crisis on specific bioregions. Point in case are the reports by the Worldwatch Institute, the United Nations (UN), the World Wildlife Foundation (WWF), the Nicholas Stern Commission, and mainly the Intergovernmental Panel on Climate Change (IPCC). These reports proceed to stimulate debates on global politics and in the context of civil society on how to tackle local weather change. Climate change, in particular, is one of the issues that is of utmost importance to the world agenda nowadays. This is because scientific proof has revealed, 'that climate change is an all-encompassing threat and is considered the most serious threat to the survival and sustainable development of humanity' (Oyekanmi, Amosun \& Adelekan 2019:1936). The effects of climate change are real and are being felt worldwide.

South Africa is affected by several environmental problems and extreme events that are weather-related. During the past few years, the effect of climate change on South Africa was especially noticeable. This was evident from the varied natural disasters that occurred, such as heat waves, floods, droughts, storms and wildfires (Lethoko 2014:75; UNICEF 2011:22). Within South Africa, different variables can cause substantial changes to climate change. These include a rise in temperatures, patterns of precipitation that change and differences with regard to the rate of recurrence and intensity of dangerous weather events (UNICEF 2011:7).

Against this backdrop, it is imperative to understand the direct effect that climate crisis will have on the younger generation in South Africa. Variables such as rising temperatures will have a significant and direct, physical impact on the youth. This is because it affects water security and agriculture. Consequently, this will have an immediate effect on nutrition as it causes food scarcity and hunger, while flooding and droughts can cause structural damages to buildings and roads (UNICEF 2011:30-31).

Water shortages as well as changes with regard to the colour, taste and quality are some of the most pronounced problems faced by the youth at present (Nkrumah 2021:4). In areas where less rain is received, challenges such as soil erosion, degradation of land and a decrease in agricultural food production arise. This will particularly affect children and households. Young children are most at risk to be affected. This is especially the case with threats such as a lack of healthy, safe drinking water, and lack of proper nutrition. The reason is that they are physically more vulnerable and have specific nutritional needs (UNICEF 2011:7). Also, the consequences of an increase in the environmental toxin levels and their impact on the youth seem not to be fully understood. This is despite the reality that climate change impacts the intellectual, mental, social and physical development of young people.

Furthermore, increasing temperatures affect children more adversely. This is especially the case with regard to heatstroke. Temperature projection shows an upsurge in the amount of days and nights that will be hot, especially for the inlands of South Africa. The 'urban heat island effect' could have a strong effect leading to increased temperatures in the urban areas. Children who are disproportionately excluded and underdeveloped will be more severely impacted by climate change (UNICEF 2011:7).

Negative changes may be induced on intra-household dynamics as a result of the emotional distress caused by factors such as 'a reduction in access to basic services, illness, displacement or damage to houses as a result of flooding' (UNICEF 2011:7). This can also impact children and the youth destructively as they may drop out of school because of floods. Again, this will impact their academic achievement in a negative way (UNICEF 2011:7).

Climate change has a significant influence on schools. Schools in South Africa face the threat of a shortage of water because of droughts. Furthermore, there is the threat of water contamination because of infectious agents and toxins as a result of floods. In South Africa, water safety is of utmost importance. This is because $30 \%$ of the educational institutions that is schools use pit latrines or they lack a toilet (Chersich et al. 2019:615). Continuing with the negative impact of climate change, these scholars postulated that most 
infections that originate from water or food, especially those that consist of bacteria, are affected by higher temperatures. This is important, especially with regard to adolescents where a lack of distance between students increases the chance that infections may be spread (Chersich et al. 2019:615). Warmer weather and temperature variations can worsen asthma amongst teenagers. This also seems to be more so in the case of adolescents than other age groups. An increase in dust and pollen, as well as air pollution, is another consequence of climate change. This leads to more instances of asthma and allergies amongst adolescents. Higher temperatures also increase exposure to toxic substances in the environment. This poses a risk because many of the South African schools are closely situated in areas that contain toxic substances such as: roads that contain heavy traffic, mining dumps and industrial plants (Chersich et al. 2019:616; Nkrumah 2021:4).

Contrary to the abovementioned direct effects, climate change also has indirect effects. An adolescent develops on a biological and cognitive level. This development occurs in the context of the environment that they live in. Therefore, social problems such as a lack of food, infrastructural damage and migration can all impact the development stages of different age groups in a major way. These impacts threaten the mental health of adolescents and may even lead to suicide. In many cases, these mental health problems persist into adulthood. Evidence provided by the UN points to one climate change disaster per week (Chersich et al. 2019:616; Nkrumah 2021:4). Even if only a small percentage of students get affected with regard to their mental health because of these disasters, it creates an immense disease burden.

Climate change is especially threatening to adolescents with pre-existing mental health issues and to those who lack psychological resilience. To minimise the occurrence of mental health problems, there should be early preventative measures before an extreme weather event (Chersich et al. 2019:616-617). Furthermore, adolescents should not only be involved in reducing the risk of disasters but helping with the recovery also. The effects of temperature on academic achievement have been well researched. Chersich et al. (2019:616-617) were of the opinion that educational performance is affected by high weather temperatures, not only during examinations but also by the cumulative exposure to higher temperatures throughout the academic year.

I have so far discussed some of the effects that the climate crisis has on our children and youth's mental health, intellectual development and physical health. However, developing sustainably and achieving key development targets are threatened by a change in the climate. This includes the older 'Millennium Development Goals (MDGs) and the newer Sustainable Development Goals (SDGs)' (cf. Tomalin et al. 2018 \& 2019). Because of this, the focus of this article will now briefly be placed on the goals relating to sustainable development.

\section{A discussion on the sustainable development goals}

This article is part of a bigger study endeavour involving a number of African and German academics and practitioners on the ecological discourse, religion and sustainability. As a result, the theme of this special collection issue, 'Youth, Faith, and Environmental Consciousness: A Case for Sustainable Development' was chosen. Because climate change and environmental devastation are amongst the world's most severe challenges to human race and long-term development, I believe that it is necessary (albeit briefly discussed in this contribution) to draw a link between the SDGs, sustainable development, climate change, and the pivotal role that youth can play in averting climatic disaster.

The MDGs were revised by the UN in September 2015. A 15year global agenda was defined and a new title, 'Transforming our World: the 2030 Agenda for Sustainable Development' was used (Sengupta 2016:1). 'Sustainable Development Goals (SDGs) target the positive change in socioeconomic natural systems on a global level' (Rant 2020:1). They aim:

$[T]$ o reduce poverty; to protect natural resources and the planetary atmosphere; to promote gender equality and human rights; to improve the quality of living; to spread peace; and implement other indicators of planetary and humanistic wellbeing across the globe. Altogether, there are 17 Sustainable Development Goals disassembled in 169 targets. (p. 1)

I believe that 10 out of the 17 SDGs are either directly or indirectly linked to this article and they are:

$[N]$ o poverty (SDG 1), Good health and well-being (SDG 3), Gender equality (SDG 5), Clean water and sanitation (SDG 6), Affordable and clean energy (SDG 7), Sustainable cities and communities (SDG 11), Responsible consumption and production (SDG 12), Climate action (SDG 13), Life below water (SDG 14), Life on land (SDG 15) and Partnerships for the goals (SDG 17). (Rant 2020:1)

The abovementioned SDGs are so interwoven that one has an immediate effect or impact on the other. For example, the negative impact of climate change and other major environmental issues can be attributed to human race and creates problems with regard to poverty reduction (SDG1) (Gas-Aixendri \& Albareda-Tiana 2019:1). This necessitates international cooperative efforts (SDG17). Researchers and activists for decades have been trying to get world leaders' serious attention with regard to climate change. Still, there is no synergy or progress visible with regard to economic, social and environmental variables. A similar concern that highlights how SDGs are interwoven is the fact that certain doings of humans, such as deforestation, the use of fossil fuels and unsustainable agriculture, contribute to climate change. This leads to an increase in the unavailability of nutritious food and potable water. It also destroys environmental ecosystems and jeopardise the safety of living environments. The consequences include: malnutrition, being prone to illness and migrating to other areas. This leads to an increased vulnerability amongst the youth. 
The notion of sustainable development in this regard specifically refers to a group of initiatives on a socio-political, economic and technical level. These initiatives aim to change the future of communities. The World Commission on Environment and Development (1987), published a report in 1987 (Our Common Future), ${ }^{2}$ wherein the commission defines sustainable development as 'development that meets the needs of the present without compromising the ability of the future generations to meet their own needs' (p. 24). However, this goal cannot be achieved because climate change poses a threat to the future of the youth (Sanson, Van Hoorn \& Burke 2019:201). The climate crisis and the accompanying extreme weather effects might, in fact, reduce agricultural and animal production. As a consequence, food prices will increase, jobs in the agricultural sector will be lost, and poverty will increase. Because of this, an urgent need to strengthen resilience and efforts towards mitigation has arisen. The purpose is to secure people's access to essential living needs. In this regard, Goal 13 of the SDGs demands that states undertake 'urgent action to combat climate change and its impacts'. They must do so through various measures such as strengthening adaptive capacity, creating awareness, advocating environmental consciousness, integrating measures in national planning to fight the climate crisis, meaningfully mitigating actions and improving mechanisms for marginalised people, such as women and adolescents, to participate (Nkrumah 2021:3).

Therefore, to achieve the SDGs, people in the whole world, and not only governments, must play an active role and contribute. To promote and achieve SDGs, people and social agencies with deep-seated values and altruistic motives need to adapt their actions and embark on citizen campaigns. Therefore, to secure and ensure a sustainable future, with the earth being a safe home for humanity, all social entities must participate.

It is acknowledged that all generations must be involved in this seemingly overwhelming task. However, it is beyond the scope of this research to include all generations. Therefore, the focus will be on the youth and their role and ability to get involved and bring about change with regard to the climate crisis and issues pertaining to environmental consciousness.

\section{The role of the youth as game- changers}

In less complicated terms, sustainable development is concerned with the modern-day generation, the youth, without jeopardising the future generations (Conradie 2011:23). Therefore, the youth are right in the centre of the ecological (in)justice, environmental consciousness and climate change discourse.

Youth movements and activism are on the rise across the globe on issues such as ecology, climate change and environmental injustice. In Europe, the 17-year-old teenage activist from

2.This World Commission on Environment and Development report, which is entitled 'Our Common Future', is also known as the Brundtland report (1987) (cf. GasAixendri \& Albareda-Tiana 2019:3).
Sweden, Greta Thunberg, conducts a lively and ongoing engagement and campaign for action on environmental injustice and problems with regard to climate change. Her 'How dare you' - speech addressed the leaders of the world on their failure to act at the UN's climate change summit of September 2019. This speech provoked several contradictory viewpoints. It is not the purpose of this article to discuss the reactions and provocations of Greta Thunberg's speech. What I want to illuminate is how within months, a teenage activist has influenced the global discourse on the theme of the youth and climate change. Of further interest is Greta Thunberg's activism with regard to environmental issues and the social movement that was created by it. Greta Thunberg started protesting at the age of 15. At this age, she decided not to go to school on Fridays. She rather chose to spend days outside the parliament of Sweden (Stoecklin 2021:1). The purpose of this protest was to demand stronger government action on climate change. Shortly after, students followed and did the same as they also took to the streets (Stoecklin 2021:1). A school climate strike movement under the name, 'Fridays for Future', was launched by them. Following Greta Thunberg's speech at the United Nations Climate Change Conference in 2018, youth dissent around the world has increased (cf. Stoecklin 2021). In 2019, there was more than one coordinated multi-city demonstration that involved more than a million students apiece (Boulianne, Lalancette \& Ilkiw 2020:208). This was the impact that one teenage activist had in a European country such as Sweden. Will the vulnerable youth in Africa, with fewer resources, and perhaps more to lose by not going to school, have the same impact?

However, engaging the youth in raising awareness on issues of climate change globally, remains crucial. This is because the vulnerable youth and those living in poverty may be the victims of climate change and environmental injustice. This is while those who are living comfortably or who are affluent would probably be affected differently. They may also find the necessary resources to escape the direct threads of climate change in terms of food, shelter and safety. Conradie (2008:7) elaborated on this and said that all predictions point to the fact that Africa's impoverished population will be 'the most vulnerable' as pertaining to climate change. Widespread poverty limits a country's ability to adapt to adverse conditions. Certain factors worsen this situation. These include: recurrent droughts and floods, scarcity of fresh water, higher dependence on natural resources and poor health care system. A further factor that has an impact is an international system where those who control the financial playground and the means of production are favoured. This will have serious consequences with regard to a range of issues such as hunger, malnourishment and desertification. It will also contribute to health issues such as malaria and water-borne diseases such as cholera. Environmental refugees will stretch the ability to cope in migrant countries and this will increase the potential for violent conflict. One may conclude that climate change, environmental and ecological justice can scarcely be ignored. It must be on the social agenda of the African youth, as they will be impacted the most. 
I am therefore in agreement with Mudombi, Nzeyimana and Weisheit (2011:2) when they said that ' $(t)$ he youth fit into the climate change and development equation, both as victims and as solution providers'. The youth are being unjustly victimised in context of the climate change as a result of actions and decisions of the current and previous older generations. The role of the youth has been influenced by the fact that they are viewed as the leaders of the future. This view has been prone to misuse as leadership is not limited to the future. This view also dismisses the role, potential and contribution that the youth can play today. The youth between the ages of 15-24 years make up 16\% of the world population. The number of youth will increase to 1.3 billion by the year 2030. The behaviour and decisions of today's leaders with regard to the climate crisis and other problems in the environment will have an impact on future generations. This principle is called intergenerational equity. The youth have specific demands with regard to climate change. They also offer more creative solutions than other age groups. This factor must be acknowledged and taken into account.

As a result of the impact of various global youth movements and their activism initiatives, the youth can be regarded as the environmental stewards of generations to come. For instance, despite what has already been mentioned so far, teenage activists have protested against climate change in various ways. Despite this, young people are still depicted as uninterested in civil action (Han \& Ahn 2020:2). It can also be argued that these are not South African youth movements and initiatives, hence shifting my focus to the South African youth.

The South African Youth Climate Movement received extensive media coverage in June 2019, as well as a significant rise in involvement (Mjiyakho et al. 2021:np). Young people from all around South Africa took part in the fight for climate justice. Historically, South African youth have always been a force to be reckoned with, capable of gradually propelling ahead a movement (cf. Booysen 2016). As with Greta Thunberg in Europe, Ayakha Melithafa, the South African 17-year old climate activist from the Western Cape (Eersterivier), has also gained prominence (cf. World Economic Forum 2020:3). She has played an important role in drawing attention to South Africa's significant climate concerns. She also made headlines when she joined Greta Thunberg and other teens from around the world as they petitioned the UN Committee on the Rights of the Child ${ }^{3}{ }^{4}$ to hold five of the world's most powerful economic powers accountable for their failure to address the climate catastrophe (cf. UNICEF 2019). In January 2020, Ayakha Melithafa joined Greta Thunberg on the platform at the

3.The United Nations Committee on the Rights of the Child received a ground-breaking legal complaint about climate change from 16 youth leaders who represented different countries. It is clear from their petition that the effects and risks of climate change have been evident for decades, especially to five regional leaders and G2O members (Respondents Argentina, Brazil, France, Germany and Turkey). Despite this, emissions are not being curbed by them. Furthermore, they continue to this, emissions are not being curbed by them. Furthermore, they continue to promote fossil fuels. The crisis with regard to climate is affected by the role of a states. If they do not show leadership in this regard, the attempt to solve the crisis globally will fail. The youth petitioners are between the ages of 8 and 17. They hail from Argentina, Brazil, France, Germany, India, Palau, Marshall Islands, Nigeria, Arica, Sweden, Tunisia and the United States.

4.https://www.unicef.org/turkey/en/press-releases/16-children-including-gretathunberg-file-landmark-complaint-united-nations.
World Economic Forum in Davos, Switzerland (cf. World Economic Forum 2020:3). Melithafa has also called for an immediate halt to South Africa's coal, oil and gas extraction.

On Friday, 14 June 2019, the youth marched in Pretoria and Cape Town as they demanded that the government act immediately and urgently on the climate crises (Postman \& Hendricks 2019:np). The African Climate Youth Alliance initiated the protest that was a follow-up to a march that was held on 15 March 2019. The South African youth demand that government should acknowledge that there is a climate crisis. They also want a moratorium on new oil, gas and coal mining licenses. They want the country to have $100 \%$ renewable energy by 2030. Lastly, a revision in the education curriculum is demanded so that climate change becomes a mandatory aspect of it (Postman \& Hendricks 2019:np).

Although certain youth movements and protests campaigns can be viewed as disruptive by some, disruptive dissent according to O'Brien, Selboe and Hayward (2018:5) can be viewed as a type of activism. It happens when young people who are worried about the climate catastrophe attempt to persuade economic and political leaders to take action. Norms, regulations, rules and institutions are a few examples of these. Disruptive activities are designed to put pressure on power structures and the political leaders who sustain them. Collective protests are a common way for this to happen. Therefore, the actions of young people who are involved in protests, disrupting international or national climate meetings can be classified as an act of disruptive dissent. They do it to highlight the hypocrisy and the exclusion of crucial people or to express important issues through political protests. However, although this is the case, this disruptive opposition enhances awareness of the climate emergency's underlying economical, political and social drivers. It also emphasises the aspects of justice and equity. Furthermore, it acknowledges the role of multiple interacting processes on a global level. It recognises that climate problems and solutions are systemic in nature (O’Brien et al. 2018:5).

As mentioned earlier, while climate change is not new, real emphasis was only placed on this issue during the last decade. In South Africa, it is evident from what I have argued so far, that the youth have contributed tremendously to the debate during the last couple of years. Through their actions, they have put these concerns on the national agenda. This confirms why I say that the youth are gamechanging role-players in this discourse. Other reasons why the youth should be regarded as game-changing roleplayers are:

- Blame and responsibility with regard to the climate catastrophe can be attributed to past generations, governments, leaders, policymakers and the media. Youth activists, on the other hand, have defined themselves as leading role-players. They see themselves as change agents capable of altering the status quo in a variety of ways (Han \& Ahn 2020:10). 
- The youth in South Africa have a history of contributing to change. By illustrating their freedom of expression, as allowed by the South African constitution, they have contributed tremendously during the apartheid era by expressing their concerns against the injustices of the past. In this way, they changed the status quo and social fabric of South Africa. This was also demonstrated by the youth during the recent uprising of movements like \#FeesMustFall and \#RhodesMustFall (Booysen 2016:1-20).

- Being disruptive has many advantages. It raises awareness and participation, emphasises justice and fairness, focuses on the root causes of the climate problem and provides opportunities for new participants $\left(\mathrm{O}^{\prime} \mathrm{Brien}\right.$ et al. 2018:8).

- As a demographic category, the youth have a diverse profile with regard to their frames of reference. The youth also differ with regard to their sense of agency and responsibility. The cognitive ability of individuals to comprehend complex issues is influenced by their level of development. In general, young people are engaged in a process of progressively defining their own position in relation to the environment (O'Brien et al. 2018:8).

- The youth are technologically inclined. As such, the role of technology and social media should not be taken for granted. For young people, social media is a great way to exchange information and raise awareness about important issues and it has been proactively utilised to expand the climate justice movement in South Africa. Many other young people have come to know and learn more about the climate crisis and its consequences, by surfing on the Internet and social media platforms. Young activists influence other disengaged youth by using social media platforms.

- Youth movements and activists have not only forced discussions with the government but have also motivated and encouraged other groups to join them. It has always been important for young movements to collaborate with other organisations, schools and unions.

- Furthermore, climate movements led by the youth have had a tremendous impact. It influenced climate-change policies and policymakers in South Africa. Youth movements led to the creation of the Climate Change Bill by the South African Government. In addition, hundreds of youth in South Africa have contributed to the Youth Climate Action Plan (YCAP) (Evans 2021:np). This is a civil-society movement to bring together young people's opinions on climate change. This YCAP paper will assist policymakers in comprehending the viewpoints of youth. It will also assist with the preparations for international conferences such as the United Nations Climate Change Conference (COP26). Furthermore, it will contribute to the determination of South Africa's nationally determined commitments under the Paris Agreement. ${ }^{5}$

- The youth acknowledge the importance of environmental consciousness and further education as

5.The Paris Agreement on Climate Change is a legally binding international agreement on this specific subject of climate change. indicated in the South African Youth declaration to COP 24 and COP25,

[T]he South African Youth Delegate needs to be provided with training and exposure to the climate change discourse and negotiation processes. Assuch, we recommend theimplementation of clear and decisive policies and collaborations with different youth-based entities, to train selected young people, and put forward clear expectations that government has for these youth delegates. (South African Youth statement to COP24 2018:1; cf. South African Youth statement to COP25 2019:1)

With regard to capacity enhancement, they also stated further that:

Guided by Articles 11 and 12 of the Paris Agreement on capacity building, we call on the inclusion of youth-friendly, accessible mechanisms to educate young people on the adverse effects of climate change and capacitate them to create solutions to this global crisis. We call upon government to support initiatives, that exist outside of key policy windows, to create a culture of continuity with regards to climate change. The need for increased Global South participation cannot be ignored. (South African Youth statement to COP24 2018:1; South African Youth statement to COP25 2019:1)

- The youth movement was successful in increasing awareness of the climate catastrophe as a critical global issue that must be addressed. They also successfully communicated grassroots concerns to policymakers.

- The youth advocate for decision-making powers and being equal role-players in governmental structures and policy-making structures.

- The mobilisation of the youth demonstrated their potential to take the lead in an active and responsible manner. This is especially significant at a time when governments have neglected their commitment to combatting the climate crisis.

- Youth climate activists and movements resisted preconceptions that robbed them of agency, casting them as victims of the climate catastrophe and suffering from psychological and physical distress. They have also overcome preconceptions and stereotypes that depicted them as politically illiterate, ignorant and self-centred people (cf. Han \& Ahn 2020). According to these stereotypes, they are uninterested in current affairs, collaboration with others, or tackling concerns such as the climate catastrophe.

Although there is an increase in advocacy amongst the youth, it must also be acknowledged that there is still a lack of youth representation in politics on a global level. As a result, they are generally missing from climate change policymaking, while in many countries, especially in Africa, the youth constitute the majority of the populace. They have an increasingly strong social and environmental awareness. This has the energy and potential to radically change our societies in the direction of a low-carbon and climate-resilient future.

\section{Conclusion}

With this article, I acknowledge that climate change, environmental crisis and ecological injustices are on the 
agenda of various youth activists of the global north, such as Greta Thunberg. It is also on the agenda of various organisations and institutions. However, this research explored the involvement of the Southern African youth and the potential contribution they can make to the South African context and leaders. This article accentuated that the effect of climate change is well researched and documented. However, despite this and notwithstanding various pleas to leaders for action, there still appears to be a passivity amongst leaders and government to address this issue. Therefore, I have argued that the youth are game-changing role-players and should be utilised as they can be more influential on different levels. They can do so by influencing political leaders, religious leaders and citizens. They can also influence their peers to become agents of change.

The view of the youth as active participants of future climate policymaking illustrates the urgent need to recognise them as competent citizens. It is also important to meaningfully engage them in deliberative processes. Youth inclusion is critical for progress towards a more sustainable and environmentally friendly future. Participation by young people worldwide will also help future generations to realise the importance of dealing with climate change especially with regard to the future. It is crucial to note that by advocating for the involvement of young people, the article is claiming that the youth have untapped potential that needs to be utilised and recognised by older generations and current political leaders. Therefore, the opinions of the youth must also be considered with regard to environmental interventions. The youth are crucial stakeholders because of their capability to act as agents of social change and to function as sources of knowledge, and moreover they bear a fundamental transformative potential.

\section{Acknowledgements}

\section{Competing interests}

The author declares that he has no financial or personal relationships that may have inappropriately influenced him in writing this article.

\section{Author's contributions}

J.W.B. is the sole author of this article.

\section{Ethical considerations}

This article followed all ethical standards for research without direct contact with human or animal subjects.

\section{Funding information}

This research received no specific grant from any funding agency in the public, commercial, or not-for-profit sectors.

\section{Data availability}

Data sharing is not applicable to this article as no new data were created or analysed in this study.

\section{Disclaimer}

The views and opinions expressed in this article are those of the author and do not necessarily reflect the official policy or position of any affiliated agency of the author.

\section{References}

Awojobi, O.N. \& Tetteh, J., 2017, 'The impacts of climate change in Africa: A review of the scientific literature', Journal of International Academic Research for Multidisciplinary 5(11), 39-52.

Booysen, S., 2016, 'Introduction', in S. Booysen (ed.), Fees must fall: Student revolt decolonisation and governance in South Africa, pp. 1-20, Wits University Press, Johannesburg.

Boulianne, S., Lalancette, M. \& IIkiw, D., 2020, 'School strike 4 climate: Social media and the international youth protest on climate change', Media and Communication 8(2), 208-218. https://doi.org/10.17645/mac.v8i2.2768

Cattell, J., 2021, "'Change is coming": Imagined futures, optimism and pessimism among youth climate protesters', Canadian Journal of Family and Youth 13(1), 1-17. https://doi.org/10.29173/cjfy29598

Chersich, M.F., Scorgie, F., Wright, C.Y., Mullick, S., Mathee, A., Hess, J. et al., 2019 'Climate change and adolescents in South Africa: The role of youth activism and the health sector in safeguarding adolescents' health and education', South African Medical Journal 109(9), 615-619. https://doi.org/10.7196/SAMJ.2019.v109i9.14327

Conradie, E.M., 2008, The church and climate change, Sings of the Times Series Volume 1, Cluster Publication, Pietermaritzburg.

Conradie, E.M., 2011, Christianity and Earthkeeping: In search of an inspiring vision, Sun Press, Stellenbosch.

Evans, J., 2021, 'The making of the first SA Youth Climate Action Plan', The Daily Maverick, 20 August 2021, viewed 21 August 2021, from https://www. dailymaverick.co.za/article/2021-08-20-the-making-of-the-first-sa-youth-climateaction-plan/.

Gas-Aixendri M. \& Albareda-Tiana, S., 2019, 'The role of religion in global sustainability: A study on Catalonia's contribution to sustainable development goals', in W. Leal Filho \& A. Consorte McCrea (eds.), Sustainability and the humanities, pp. 1-18, Springer, Cham.

Han, H. \& Ahn, S.W., 2020, 'Youth mobilization to stop global climate change: Narratives and impact', Sustainability 12(10), 4127. https://doi.org/10.3390/su12104127

Lethoko, M., 2014, 'Children and youth as agents of climate change impact in South Africa', Commonwealth Youth and Development 12(10), 75-91. https://doi. org/10.25159/1727-7140/1609

Mjiyakho, Y.C., Les Kapsosideris, N., Farista, S., Thornton, S. \& Banganayi, T., 2021 'Young people and the climate crisis: the challenge of building an intersectional justice movement', The Daily Maverick, 07 March 2021, viewed 24 May 2021 from https://www.dailymaverick.co.za/article/2021-03-07-young-people-andthe-climate-crisis-the-challenge-of-building-an-intersectional-justicemovement/.

Mudombi, S., Nzeyimana, E. \& Weisheit, A., 2011, A youth perspective on climate change opportunities and challenges for climate resilient development, Young Professionals Platform for Agricultural Research for Development (YPARD - Africa), pp. 2-11.

Nel, R., 2016, "'Children must be seen and heard" - Doing postcolonial theology with children in a (southern) African Reformed church', HTS Teologiese Studies/ Theological Studies 72(1), a3565. http://dx.doi.org/10.4102/hts.v72i1.3565

Nkrumah, B., 2021, 'Beyond Tokenism: The "born frees" and climate change in South Africa', International Journal of Ecology 2021, 1-10. https://doi.org/10.1155/ 2021/8831677

O'Brien, K., Selboe, E. \& Hayward, B.M., 2018, 'Exploring youth activism on climate change dutiful, disruptive, and dangerous dissent', Ecology and Society 23(3), 1-14. https://doi.org/10.5751/ES-10287-230342

Oyekanmi, O.O., Amosun, P.A. \& Adelekan, I.O., 2019, 'Effects of mentoring and field study instructional strategies on students' climate change reduction practices in social studies in Lagos State', in W. Leal Filho (ed.), Handbook of climate change resilience, pp. 1935-1955, Springer, Cham.

Postman, Z. \& Hendricks, A., 2019, 'South African youth take to the streets over climate change: Hundreds protest in Johannesburg and Cape Town', News Article, viewed 23 May 2021, from https://www.groundup.org.za/article/south-africanyouth-take-streets-climate-change/.

Rant, M.B., 2020, 'Sustainable development goals (SDGs), leadership, and Sadhguru: Self-transformation becoming the aim of leadership development', The International Journal of Management Education 18(3), 100426. https://doi. org/10.1016/j.ijme.2020.100426

Sanson, A.V., Van Hoorn, J. \& Burke, S.E.L., 2019, 'Responding to the impacts of the climate crisis on children and youth', Child Development Perspectives 13(4), 201-207. https://doi.org/10.1111/cdep.12342

Sengupta, M., 2016, The Sustainable Development Goals: An assessment of ambition E-International Relations, viewed 24 May 2021 from https:/www.e-ir. info/2016/01/18/the-sustainable-development-goals-an-assessment-of-ambition/.

South African Institute of International Affairs Youth Policy Committee and the South African Youth Climate Change Coalition, 2018, South African Youth Statement to COP24, Presented to the Department of Environmental Affairs at the Extended NCCC Stakeholder Dialogue, Benoni, 06 November 2018. viewed 20 May 2021, from Stakeholder Dialogue, Benoni, 06 November 2018. viewed 20 May 2021, from
https://www.environment.gov.za/sites/default/files/docs/southafrican_ youthstatementtoCOP24.pdf. 
South African Youth Statement to COP25, 2019, viewed 20 May 2021, from https:// saiia.org.za/wp-content/uploads/2019/10/COP-25-Youth-Statement_Final_ SD.pdf.

Statistics South Africa, 2019, South African population reaches 58.8 million, viewed 24 May 2021, from http://www.statssa.gov.za/?p=12362.

Stoecklin, D., 2021, 'The transactional horizons of Greta Thunberg', Societies 11(36), 1-24. https://doi.org/10.3390/soc11020036

Tomalin, E., Haustein, J. \& Kidy, S., 2018, Religion and the sustainable development goals, Cambridge Institute on Religion \& International Studies, Clare College, Cambridge.

Tomalin, E., Haustein, J. \& Kidy, S., 2019, 'Religion and the Sustainable Development Goals', Review of Faith \& International Affairs 17(2), 102-118. https://doi.org/10.10 80/15570274.2019.1608664
UNICEF, 2011, Exploring the impact of climate change on children in South Africa, UNICEF South Africa, Pretoria.

UNICEF, 2019, 16 children, including Greta Thunberg, file landmark complaint to the United Nations Committee on the rights of the child, Child petitioners protest lack of government action on climate crisis, UNICEF Media Release, viewed 23 May 2021, from https://www.unicef.org/turkey/en/press-releases/16-childrenincluding-greta-thunberg-file-landmark-complaint-united-nations.

World Commission on Environment and Development, 1987, Report of the World Commission on environment and development: Our common future, Brundtlan Report, A/42/427, United Nations General Assembly, 04 August 1987, pp. 1-374 viewed 23 May 2021, from https://digitallibrary.un.org/record/139811? In=en.

World Economic Forum, 2020, 10 teenage change-makers at the annual meeting 2020, viewed 23 May 2021, from http://www3.weforum.org/docs/WEF_AM20_10_ Teenage_Change_Makers_at_AM20_Brochure.pdf. 